\title{
Toward a New Comparative Musicology
}

\author{
Patrick E. Savage ${ }^{1}$ and Steven Brown ${ }^{2}$ \\ ${ }^{I}$ Department of Musicology, Tokyo University of the Arts \\ ${ }^{2}$ Department of Psychology, Neuroscience \& Behaviour, McMaster University
}

We propose a return to the forgotten agenda of comparative musicology, one that is updated with the paradigms of modern evolutionary theory and scientific methodology. Ever since the field of comparative musicology became redefined as ethnomusicology in the mid-20th century, its original research agenda has been all but abandoned by musicologists, not least the overarching goal of cross-cultural musical comparison. We outline here five major themes that underlie the re-establishment of comparative musicology: (1) classification, (2) cultural evolution, (3) human history, (4) universals, and (5) biological evolution. Throughout the article, we clarify key ideological, methodological and terminological objections that have been levied against musical comparison. Ultimately, we argue for an inclusive, constructive, and multidisciplinary field that analyzes the world's musical diversity, from the broadest of generalities to the most culture-specific particulars, with the aim of synthesizing the full range of theoretical perspectives and research methodologies available.

Keywords: music, comparative musicology, ethnomusicology, classification, cultural evolution, human history, universals, biological evolution

This is a single-spaced version of the article. The official version with page numbers 148-197 can be viewed at http://aawmjournal.com/articles/2013b/Savage_Brown_AAWM_Vol_2_2.pdf.

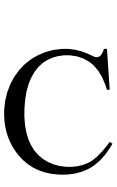
omparative musicology is the academic discipline devoted to the comparative study of music. It looks at music (broadly defined) in all of its forms across all cultures throughout time, including related phenomena in language, dance, and animal communication. As with its sister discipline of comparative linguistics, comparative musicology seeks to classify the musics of the world into stylistic families, describe the geographic distribution of these styles, elucidate universal trends in musics across cultures, and understand the causes and mechanisms shaping the biological and cultural evolution of music. While most definitions of comparative musicology put forward over the years have been limited to the study of folk and/or non-Western musics (Merriam 1977), we envision this field as an inclusive discipline devoted to the comparative study of all music, just as the name implies.

The intellectual and political history of comparative musicology and its modern-day successor, ethnomusicology, is too complex to review here. It has been detailed in a number of key publications - most notably by Merriam (1964, 1977, 1982) and Nettl (2005; Nettl and Bohlman 1991) - and succinctly summarized by Toner (2007). Comparative musicology flourished during the first half of the twentieth century, and was predicated on the notion that the cross-cultural analysis of musics could shed light on fundamental questions about human evolution. But after World War II-and in large part because of it - a new field called ethnomusicology emerged in the United States based on the paradigms of cultural anthropology. This field generally eschewed comparative analyses in favor of single-culture ethnographies based on extensive fieldwork. In addition, it focused on the analysis of non-acoustic aspects of music - such as behavior, meaning, pedagogy, gender, and power relations - over the 
acoustic analysis of musical sound, such as scales and rhythms.

We believe that the time has come to reestablish the field of comparative musicology. Recently, a number of proposals have shown promise in reintroducing various types of scientific, comparative, evolutionary, and/or acoustic methodologies into the study of the world's musics. These include "cognitive musicology" (Huron 1999), "evolutionary musicology" (Wallin, Merker, and Brown 2000), "empirical musicology" (Clarke and Cook 2004), a revived "systematic musicology" (Schneider 2008), "computational ethnomusicology" (Tzanetakis et al. 2007), and "analytical studies in world music" (Tenzer 2006). While such methodological developments are important, what has yet to emerge from these movements is a return to the unanswered questions of comparative musicology, questions that motivated such pioneering researchers as Carl Stumpf, Erich von Hornbostel, Curt Sachs, and later Alan Lomax.

Our aim here is not to dwell on comparative musicology's troubled past, but instead to point toward a bright future by applying new methodologies and paradigms to some of its unanswered questions. This field should not be seen as a replacement for ethnomusicology or historical musicology but as a specific stream within the overall umbrella of musicology. We see the new comparative musicology as a multidisciplinary enterprise in which the acoustic and evolutionary focus of traditional comparative musicology is combined with the humanistic and ethnographic approaches that have dominated the study of the world's music since the 1960s.

In order to take a first step towards the reestablishment of comparative musicology, we outline in this article what we see as five principal research issues of this field: (1) classification, (2) cultural evolution, (3) human history, (4) universals, and (5) biological evolution. For each of these issues, we focus on presenting key concepts and terminology, with the parallel aim of addressing traditional objections that have been raised against these issues in the past. In some cases, resistance appears to be due more to terminological confusion than to theoretical disagreements. Throughout this discussion, we emphasize the importance of creating objective, musicologically inspired databases and of quantitatively assessing the relationship between acoustic and non-acoustic (i.e., behavioral, semiotic) patterns, both within and between cultures.

In order to help guide the reader through this discussion, we provide a graphic flowchart in Figure 1 that demonstrates these five key areas of comparative musicology and their relationship to one another: (1) Classification procedures attempt to characterize degrees of similarity between musical works using musically salient features as the classification parameters. The pie charts in the figure represent the relative frequencies of three hypothetical musical types (shown as blue, red, and green) within the repertoires of two cultures. These colors might represent different scales, rhythms, performance contexts, or any other features thateither individually or in combination - might be musically appropriate for a given research question. (2) The study of cultural evolution attempts to understand how musical systems undergo change over time, both within and between cultures. The analysis includes changes that are transmitted across generations in a vertical, tree-like fashion (solid arrows) and those that are transmitted horizontally within generations by means of contact between cultures (dashed arrow). It seeks to understand how musical variants arise (blue "mutating" to red in culture 2 , symbolized by the thunderbolt arrow) and how they are transmitted (contact between the cultures results in diversification by exchanging blue and red variants). (3) Knowledge of music's cultural evolution can be useful in illuminating human history more generally, including such phenomena as migration, colonialism, globalization, and other forms of cultural contact. Music becomes employed as a "marker" of migrations whereby the geographic patterns of musical style can be compared with patterns derived from historical documents and other migration markers, such as genes, languages, or technologies. Figure 1 illustrates this graphically using two hypothetical islands, with the roots of both cultures in an ancestral culture occupying the north of the larger 
island, followed by a split as culture 2 comes to occupy the smaller island, but with continued exchange with culture 1 across the strait separating the two islands, as described in (2) above. (4) The study of musical universals attempts to identify and explain statistical trends that are shared by most or all cultures. Figure 1 shows the dominant green type as a more promising candidate universal than the more variable blue and red types. (5) One explanation for such universals is shared genes, as explored in the study of music's biological evolution. This study analyzes music's evolutionary origins and functions (graphically shown by the cartoon of people engaged in musical behavior), including Darwinian models of survival and reproductive success. The flowchart is shown in Figure 1 as unidirectional for simplicity, but in reality all of these features interact with one another, since the type of evolutionary, historical, or universalistic question being asked will affect the choice of musical samples and methodologies to be employed, and vice versa.

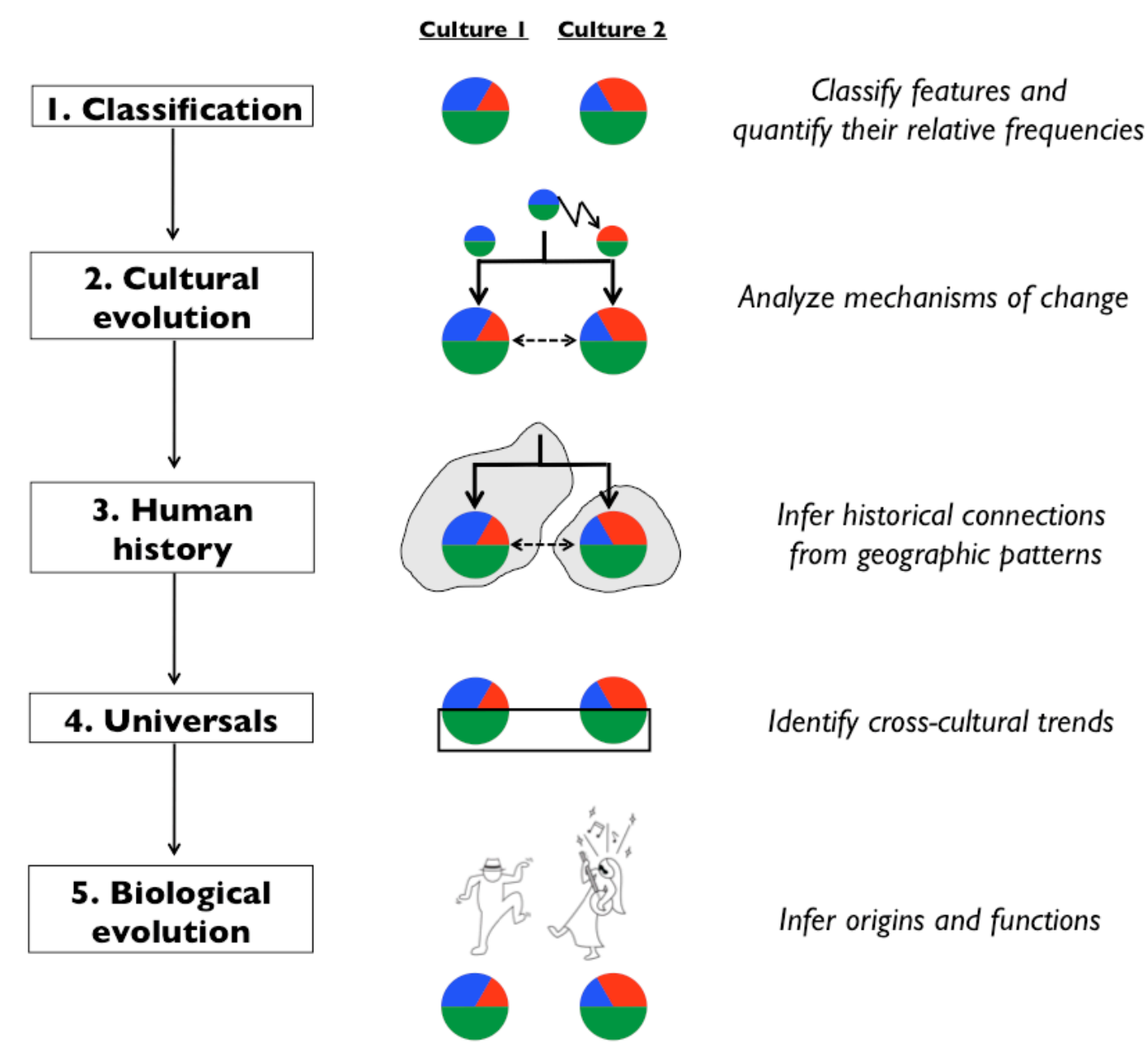

Figure 1. Five key processes that form the basis of comparative musicological analysis. The pie charts in each panel specify the relative frequencies of hypothetical blue, red, and green musical types for two different cultures (see the text for a detailed explanation). 


\section{PART I: KEY ISSUES}

\section{1) Classification, Clustering, and Maps of Music}

\author{
How can we characterize similarities between \\ different musics? \\ How can this information be used to classify musics \\ into groupings and to create musical maps that \\ represent geographic patterns?
}

Classification forms the basis of comparative analysis. There is a vast range of possible classification units, samples, features, and quantification methodologies; the choice of the appropriate ones depends greatly on the nature of the research question being addressed.

Merriam (1964) described three broad domains of music: sound, behavior and concept. To this day, classification of music has focused almost exclusively on sound. However, a major objective of the new comparative musicology is to apply classification procedures to musical behavior and meaning, just as they have been applied to numerous other ethnographic and semiotic domains (Murdock 1967; Lewis 2009). In the following descriptions, we will focus largely on examples from our own area of expertise-the acoustic features of traditional vocal songs - in order to outline concrete steps by which to proceed. We do not mean to imply that these are the best or only ways to proceed with musical classification and comparison. We believe that the same general set of classification principles and comparative methodologies could be applied equally well to instruments (Hornbostel and Sachs [1914] 1961), popular music (Middleton 1990), dance (Lomax, Bartenieff, and Paulay 1968), musical semiotics (Nattiez 1990), or sociomusicology (Feld 1984), to mention just a few areas that could be subjected to comparative analyses.

Although the goal of classification is often to explore phylogenetic (evolutionary) questions, the most basic type of classification procedure simply describes relationships in phenetic terms based on surface similarity. Modern evolutionary biology often utilizes molecular classification of DNA sequences to create phylogenies, but such work was only made possible by prior phenetic work on morphological classification of biological structures, such as organs and skeletons (Darwin 1859). Given the relative lack of understanding of the mechanisms of music evolution, we propose that musical classification be focused initially on surface similarity, although some areas (e.g., "tune family" research; Bayard 1950) show greater promise for phylogenetic classification.

\section{a) Units}

The first question that classification research has to address is: What is the appropriate unit of analysis? In many cases, an individual song, or other musical work, will serve as the optimal unit of musical classification, even when the research question addresses higher-level relationships, such as between genres, cultures, or geographic regions. This allows analyses to work with actual musical examples rather than abstractions of what a "typical" song of a given genre or culture is like (Tenzer 2006). It also allows for the analysis of within-culture as well as between-culture musical diversity (Rzeszutek, Savage, and Brown 2012; Savage and Brown forthcoming). In some cases, finer-grained units, such as schemata, phrases, or even notes, might be more appropriate. The benefits of using finer-grained units need to be weighed against the costs in terms of time and computational intensity. Ultimately, the chosen unit of analysis should be the one that best addresses the specific research questions of interest.

Although the song is often the optimal unit of analysis for classification, there can be complications in working with such a unit. For example, it is not always clear what the boundaries of a song are, especially when dealing with largescale forms with multiple movements or sections, such as occurs in some classical musics or in musics accompanying lengthy rituals. But even in situations where the boundaries of a song are indeed defined, the song might show strong heterogeneity of musical features (e.g., subsections that differ in style). In such situations, "multi-coding" is required (Lomax and Grauer 1968; Savage et al. 2012), in which a song is classified as having not a single set of stylistic features but several (see Issue 1c below). 
This can of course create complications in the comparative analysis of songs.

One caveat about performing comparative analyses is the specification of cultural groupings in such analyses. Lomax's (1968, 1976) Cantometrics project was criticized for using broad culture-areas as the basic units of his musical analysis (e.g., "Old Europe," "Arctic Asia"), rather than finer-grained groupings (Driver 1970). We advocate using ethnolinguistically defined cultural groups (Lewis 2009) as the major higher-level grouping above the song-level. For example, we suggest using Basque or Slovak instead of Lomax's "Old Europe," or using Chukchi or Ainu instead of "Arctic Asia." This approach is not perfect, but it allows for more nuanced comparisons than does using broader culture-areas, including proof-of-principle analyses of whether such cultural groupings are musically justified to begin with. Using language as a proxy for culture has proven quite successful in much comparative work in anthropology (Pagel and Mace 2004). It thus provides the additional benefit of allowing for comparability between music and other domains, such as language and genetics (see Issue 3 below). However, in some cases using finer-grained and/or different groupings (e.g., geography, age, social status, genre, composer, gender, etc.) may be more appropriate.

\section{b) Sampling}

Once a unit of analysis is established, the next step is to define a sample (a corpus). In the case of comparative analyses, the sample will usually include songs from two or more cultures. There are a number of important methodological issues related to sampling that need to be considered, such as inclusion criteria, access, sample size, and scope.

Inclusion criteria. Proper sampling requires $a$ priori decisions about which songs to include in the sample from the pool of available songs from a culture or region. Exclusion of songs can be based on a host of criteria, including genre, performers (gender, age, status), recording period, and recording quality, as well as complex issues related to authenticity in situations where native styles might have been influenced by foreign styles (e.g., of missionaries). For example, a project focusing on indigenous, ritual vocal music would a priori exclude popular music, purely instrumental music, and songs showing obvious foreign influence. Inclusion criteria must be applied consistently to prevent confirmation bias, in which researchers simply choose those samples that support their hypotheses and exclude ones that do not. When the number of available samples is too large to make a comprehensive analysis feasible, songs should be selected randomly from the pool of songs meeting the inclusion criteria.

Access to samples. A related consideration is the availability of samples as well as access to them. Typical sources of samples include commercial publications, archives, and one's own unpublished field recordings. These span a variety of media, such as written transcriptions, audio recordings, and video recordings. Because ethnomusicological field recordings are produced in uncontrolled environments, it is impossible to compile a broad comparative sample of similar songs that have been recorded under identical conditions. Recordings from well-studied cultures, and the musical genres therein, may be plentiful and may be accompanied by detailed ethnographic documentation while recordings from others may be non-existent, of poor quality, have little contextual information, or have been carried out at different times under different recording conditions. The choice of who and what gets recorded has historically depended on the music itself and on the people who perform, record, publish and consume it, the latter being dependent on factors of aesthetics, politics, social relationships, economics, and functionality. Nevertheless, careful consideration of these factors when selecting samples can mitigate problems of comparability.

Sample size. Resistance to musical comparison has often been due to comparativists' reliance on what Savage and Brown (forthcoming) have termed the "one culture = one music" model, the idea that a culture's musical repertoire can be captured by a single representative song or style (Lomax 1968). Such a model assumes that the level of withinculture diversity is negligible and that a small sampling of songs from a given culture should be sufficient to capture its style. This assumption has been strongly criticized by ethnomusicologists (Henry 1976; Feld 1984), and analyses from our lab have provided quantitative evidence against it 
(Rzeszutek et al. 2012). Sampling has to be done on a sufficient scale to encompass the breadth of musical styles that exists both within and between cultures. In general, the greater the within-culture diversity, the greater the sample size needed to provide a reasonable picture of overall patterns of musical style.

Regardless of the nature of the sample, larger sample sizes tend to allow for more robust conclusions. However, in many cases the most interesting or important samples are also the rarest, and thus it is better to choose analytical methods that are appropriate for the available sample, rather than trying to meet specific sampling quotas. That said, it is difficult to make generalizations about musics with sample sizes of less than five songs or so. In similar studies from genetic anthropology and other natural sciences, sample sizes of approximately thirty per group are generally sufficient to identify statistically significant patterns if such patterns are reasonably strong, while sample sizes exceeding 100 per group tend not to add much new information to the conclusions. A study examining traditional group songs from indigenous populations in Taiwan and the Philippines found that sample sizes of approximately thirty songs per ethnolinguistic group were sufficient to identify highly statistically significant between-population differentiation among these groups (Rzeszutek et al. 2012). Whether such sample sizes will be sufficient for other comparative musicological studies will need further empirical validation.

Scope of comparison. One of the weaknesses of early comparative musicological work was a reliance on what we will call remote comparison, in which small numbers of songs from very distant regions were compared, often to support arguments of "monogenesis" about long-distance similarity between regions. Such projects often involved the cherry-picking of particular songs that satisfied preconceptions of musical similarity. Instead of this, we generally advocate regional comparison, in which large, independent samples from neighboring cultures are submitted for comparative analysis. Such samples have the benefit of making it easier to explore historical relatedness as a potential factor in explaining similarities. From a comprehensive set of regional projects, it should be possible to generate a musical map of the world of the kind envisioned by Lomax (1968, 1976).

\section{c) Features}

The musical sample, once defined and validated, can then be subjected to classification procedures. Classification schemes embody salient features of a domain in a multidimensional manner. These features subdivide broad categories - such as pitch and rhythm in the case of music - into a series of relatively independent characters, such as "hemitonicity" (presence of semitones), "melodic range," "meter," or "durational variability" (Savage et al. 2012). Each character is in turn comprised of a series of character-states specifying a possible range of variation for that character, such as the character-states "small," "medium," and "large" for melodic range. Once the classification scheme is specified, it is then used to "code" the songs of the sample. Such coding involves selecting the character-state(s) that best describes the song for each character.

Classification schemes. Musics are complex, multidimensional phenomena; therefore, classification schemes for music have to be complex and multidimensional. More importantly, classification schemes should aspire to be universal so as to accommodate features present in any musical style throughout the world. While this is a tall order for any classification scheme, serious attempts have been made in this direction. Broad classification schemes, such as Hornbostel and Sachs's ([1914] 1961) instrument classification scheme, Lomax and Grauer's (1968) Cantometric song classification scheme, or the related CantoCore scheme of Savage et al. (2012), provide more scope for cross-cultural comparison than regional classification schemes - such as the classical theory systems of Western scales, Indian ragas, or Arabic maqamat - that are designed to apply to the music of specific cultures. However, such culture-specific systems may provide more nuanced and appropriate measures when the scope of comparison is limited to specific regions. The important points are that the types of features used for classification be 
musicologically appropriate for the research questions being addressed, that the classification schemes be defined as clearly and objectively as possible, and that they be applied consistently so as to allow for reliable comparisons and independent replications when applied by different researchers.

Characters and character-states. As mentioned above, the characters of a classification scheme attempt to embody significant features of form. In the CantoCore classification scheme that we developed (Savage et al. 2012), we included twentysix structural characters of music that span the broad domains of rhythm, pitch, text, texture, and form. Each of the twenty-six categories contains between three and six character-states. In general, the more types of features used for classification, the more detailed, robust, and flexible the resulting patterns should be, although there is always a tradeoff between the comprehensiveness of the scheme and the time required to code songs.

A fundamental distinction in classification theory is that between ordinal features and nominal features (Stevens 1946). Ordinal features can be classified in increasing order of size (e.g., small, medium and large for musical intervals) or frequency (e.g., low to high frequency of vocables in a song). Nominal features, by contrast, cannot be placed onto a numerical spectrum of size or frequency, and are instead organized as a series of unordered states. For example, melodic contours come in a variety of qualitatively distinct types, such as descending contours, ascending contours, arched contours, and the like.

Coding. Once the characters and characterstates of a classification scheme are specified, the next step is to code all of the songs of a sample by selecting the character-state of each category that best applies to each song. This can be done subjectively (e.g., by ear) or objectively (e.g., using physical measurements or automated algorithms), or by some combination of the two. In some cases, etic (objective, outsider) representations may differ from emic (insider, subjective) ones (Harris 1976). The choice of the appropriate method(s) will depend on the goals of the researcher and the degree of accuracy and reliability of the resulting classifications. Some researchers have attempted to explore this issue using innovative techniques that combine subjective and objective measurements, such as Perlman and Krumhansl's (1996) study of interval-category conceptualizations among Javanese gamelan musicians and Western classical musicians. Such studies have demonstrated complex differences in representations both within and between cultures. This complexity emphasizes the need for care in designing and interpreting classification research in ways that are both reliable and useful.

In situations of internally heterogeneous songs, it is sometimes necessary to "multi-code" the song-in other words, to select more than one characterstate for a song. Likewise, when songs lack particular features altogether, it is necessary to code them as "null." For example, if the classification scheme specifies features of multipart music and the song in question is a solo vocal song, then the song would have to be coded as null for all multipart features related to texture.

Classifying non-acoustic features of music. Objections to comparison have often focused on past reliance on acoustic features-particularly structural features such as the scales or meters that are prominent in Western music theory-to the exclusion of other features that may be more relevant for other musical cultures. The latter include non-acoustic features, such as social function or symbolic meaning, as well as acoustic features such as performance style, micro-rhythms, or micro-tonality (Blacking 1977). To date, classification schemes have tended to focus on acoustic features related to performance (Lomax and Grauer 1968) and structure (Savage et al. 2012), although Hornbostel and Sachs's ([1914] 1961) influential instrumental classification scheme also incorporates elements of sound-production mechanisms that are not necessarily audible. An important goal of the new comparative musicology is to establish classification schemes that objectively and reliably classify non-acoustic features such as behavior and semiotic meaning (e.g., Feld 1984; Nattiez 2000), so as to permit comparative analyses of such features. This will be a crucial step toward mitigating the Eurocentric bias of earlier comparative musicology, which placed excessive emphasis on pitch-related features derived from Western classical music theory (Toner 2007). 


\section{d) Quantification}

A principal goal of classification is the establishment of clusters of stylistic similarity, either within or between cultures. This is analogous to the establishment of language families (Greenberg 1957; Lewis 2009) or other types of families of similarity. Taking comparison seriously requires moving beyond simple dichotomies - such as same/different or present/absent - and instead examining the degree of similarity between songs and the relative frequencies of features between cultures, as represented by the pie charts in Figure 1. Such an approach allows us to move beyond the "one culture = one music" model toward more nuanced geographic maps of musical style (Savage and Brown forthcoming), which in turn can be useful in elucidating the history of migrations and cultural interactions (see Issues 2 and 3 below).

As mentioned previously, classification proceeds through the generation of classification schemes comprised of key characters, each of which contains multiple character-states. These schemes are then used to code the songs that make up the sample under study. Using this coding information, the next step is to apply statistical clustering techniques to the data in order to measure musical similarity among the songs in the sample and to group those songs into clusters of similarity. It is then possible to look at these clusters a posteriori and infer the classification features that unite the songs of a cluster and hence distinguish that cluster from others. For example, one cluster might contain the predominantly monophonic songs of the sample while another cluster might contain the predominantly polyphonic songs. However, since classification schemes are multidimensional, clusters tend to differ from one another in a multidimensional manner. In other words, clusters can be thought of as conglomerations of musical features and hence as stylistic song-types. We have coined the term cantogroup in our work to describe stylistic song-types derived from classification procedures (Savage and Brown forthcoming).

The next step is to examine geographic patterns of musical style and to create musical maps. The simplest way to do this is the method shown in
Figure 1, namely to visualize the relative frequencies of the cantogroups in the form of a pie chart for each defined geographic or cultural grouping. For example, Savage and Brown (forthcoming) identified five major cantogroups among 259 songs from twelve indigenous populations of Taiwan. This was visualized by showing pie charts over the geographic zone for each population, where each pie represented the relative frequencies of the five cantogroups for the musical repertoire of that group. This can also be done for any individual character (e.g., mapping the relative frequencies of different meter types).

A major critique of comparative work in musicology is that it focuses on between-culture diversity at the expense of within-culture diversity in musical style. One solution to this problem has been to adapt analytical techniques from fields such as population genetics (Excoffier, Smouse, and Quattro 1992) in musically appropriate ways so as to examine this issue in a quantitative manner. For example, Rzeszutek et al. (2012) found that the level of within-culture musical diversity was strikingly higher than that of between-culture diversity ( $98 \%$ vs. $2 \%$, respectively), as measured using twenty-six structural features and a sample of 421 traditional songs from indigenous populations in Taiwan and the Philippines. In other words, only $2 \%$ of the musical variability could be attributed to systematic differences between cultures, while $98 \%$ was due to within-culture diversity. This provided empirical support for the claims of theorists defending the importance of within-culture diversity in comparative analyses (Henry, 1976; Feld 1984). However, it also showed that the between-culture component of this diversity was highly statistically significant $(p<.001)$ and was thus capturing real musical differences between cultures.

\section{2) Cultural Evolution of Music}

What are the mechanisms of musical change and stasis? How and why do musical forms emerge, become extinct, or give rise to other forms over time?

The study of music's cultural evolution deals with the basic issue of how musics change over time and 
location. As such, it is nearly synonymous with the conventional concept of "music history." While classification (Issue 1 above) can proceed by describing musical relationships in terms of phenetic (surface) similarities, cultural evolution is largely concerned with the phylogenetic (evolutionary) mechanisms underlying these similarities. This has long been a topic of interest to ethnomusicologists intrigued by situations where the same musical "surface structure" originates from very different "deep structures" (Blacking 1971).

The term "cultural evolution" has long provoked a hostile reaction among ethnomusicologists and cultural anthropologists, who associate it with outdated Spencerian notions of progressive evolution-in other words, with the ladder-like progression of cultures from simple to complex over historical time (Spencer 1875). The modern-day field of cultural evolution has long since abandoned such assumptions and has instead capitalized on the many methodological and theoretical advances from evolutionary biology that have improved our understanding of the mechanisms of and constraints on cultural change (Cavalli-Sforza and Feldman 1981; Boyd and Richerson 1985; Whiten et al. 2012). For example, linguists have developed sophisticated models of historical diversification and phonological change among language families such as Indo-European and Austronesian by utilizing detailed historical linguistic databases of hundreds of existing languages and comparing this linguistic information with reconstructions of ancient texts and artifacts that have been reliably dated (Levinson and Gray 2012). These methods could be profitably adapted to music to explore similar questions of cultural evolution that have long interested ethnomusicologists, although it is crucial to remember that music evolution does not necessarily mirror the patterns of languages, genes, or any other system (see Issue 3 below).

The official definition of "folk music" adopted in 1955 by the International Folk Music Council endorsed an explicitly evolutionary framework:

Folk music is the product of a musical tradition that has been evolved through the process of oral transmission. The factors that shape the tradition are: (i) continuity which links the present with the past; (ii) variation which springs from the creative impulse of the individual or the group; and (iii) selection by the community, which determines the form or forms in which the music survives. (International Folk Music Council 1955:23; our emphasis)

This definition included all three major evolutionary mechanisms of transmission ("continuity"), variation, and selection. Sadly, this evolutionary framework has not been widely adopted. Here we detail how it could help in the study of music's cultural evolution.

\section{a) Mechanisms of transmission}

Evolutionary transmission can occur in diverse manners, the main types being referred to as vertical (between generations; e.g., parent-child) and horizontal (within generations; e.g., peer-peer). Additionally, convergent evolution can cause the same feature to arise independently in the absence of transmission, often due to similar functional constraints or selection pressures. All of these mechanisms occur in both cultural and biological evolution, although their relative importance is subject to debate (Kroeber 1948; Doolittle 1999; Tëmkin and Eldredge 2007; Gray, Bryant, and Greenhill 2010). Evolutionary transmission has traditionally been modelled as a branching tree, emphasizing vertical transmission (as represented by the solid arrows in Figure 1). However, scholars of both cultural and biological evolution have recently explored horizontal transmission as well (see the dashed arrows in Figure 1) using models such as networks (Bryant and Moulton 2004), jungles (Tehrani, Collard, and Shennan 2010), and admixture algorithms (Pritchard, Stephens, and Donnelly 2000).

\section{b) Mechanisms of variation}

We will now discuss music's cultural evolution in terms of the two basic evolutionary processes of variation and selection, which are in turn crucial for interpreting historical and geographic patterns of migration and cultural contact, as outlined in Issue 3. The first process deals with musical forms themselves, and explores the mechanisms by which different musical variants arise. The second topic (described in Issue 2c) examines the social forces that determine which musical variants get 
transmitted to future generations and which ones die out.

The random genetic process of mutation that generates genetic variation in human populations has clear analogues in musical copy errors. These errors can occur in orally transmitted musics to give rise to the well-known diversity of folk song variants (Seeger 1966) or they can occur in notated musics, such as when copy errors accrue over time in published scores of Western classical works. In distinction to this random process are directed processes of innovation and creativity that are not found in biological evolution, such as when composers or performers intentionally introduce completely new variants that were not present in previous generations. In most cases, such variants are not created de novo but instead arise through modifications of existing material. These modifications often involve a borrowing or imitation of elements from other works. When such borrowing occurs on a cross-cultural scale, the result can be the generation of a new blend or fusion (syncretism). Well-known examples of this are African-American and Latin-American musical blends that include elements of both African and European music styles (Herskovits 1945; Merriam 1964), or the incorporation of Asian musical features into Western music by composers such as Debussy.

A fundamental issue for the analysis of musical variation involves the dependency relationships among the musical features. Does a change in one musical feature lead obligatorily to changes in other features or can each feature change independently of others? To take one example, tonal features such as scales can change independently of rhythms, such that European scales can be readily combined with African rhythms. By contrast, introducing a fixed-pitch instrument like a piano into a nonWestern ensemble tuned to a microtonal scale system will often force the ensemble to conform to Western tuning, such as occurs in a large variety of ethno-pop fusion genres. These examples are simple but they highlight the need to understand the dynamics of musical blending and the processes by which musical features can combine across stylistic boundaries to create new musical variants.
From a geographic perspective, intercultural blends can occur as the result of two major processes. First, they can occur through the movement of people, such as occurs through migration, conquest, or the journeys of itinerant musicians. In such cases, musical blends occur because the bearers of different musical traditions come into direct social contact and are able to influence one another. However, in recent times, music has shown a striking ability to diffuse in the absence of musicians, most notably through mass media distribution routes (Appadurai 1996). Hence, one of the major effects of globalization in recent years has been the spread and admixture of diverse musical styles from around the globe, often but not always accompanied by the loss of traditional musical styles (Lomax 1977). This can occur quite readily in the absence of direct social contact with Western musicians.

The geographic dispersion of musical styles through migration was a major topic of study of the early comparative musicologists, and the new comparative musicology is no less committed to this issue, not least since the modern study of human migrations offers a host of new quantitative tools to date prehistoric population movements (see Issue 3 below). The early work on Kulturkreis (culture circles) models and diffusionism was criticized for placing an undue emphasis on the movement of music independent of people. In addition, notions of musical monogenesis led to the dangerous assumption that the appearance of similar features in different cultures could be considered the result of shared ancestry (Nettl 2005). Contemporary cultural-evolutionary models acknowledge instead the importance of convergent evolution (polygenesis), the idea that the same innovation can arise independently in different locations, either by chance or due to similar constraints. The complementary phenomenon is also quite prevalent, namely that neighboring communities that do have shared ancestry can develop highly divergent musical styles over time due to factors related to geographic isolation or the desire to set themselves apart from neighbors ("schismogenesis;" Bateman 1935). These examples highlight the general benefit of performing comparative analyses on a regional 
level, rather than doing remote comparisons (Issue 1 ), and of analyzing the movement of music in light of the movement of peoples, as discussed in detail in Issue 3 below.

\section{c) Mechanisms of selection}

The generation of new variants does not, in and of itself, guarantee that these variants will become stable components of a culture's musical repertoire. So, it is important to consider the social forces and selection mechanisms that allow certain variants to be transmitted to future generations and others to die out. This is generally conceptualized in cultural evolutionary models as a process of "cultural selection" analogous to natural selection but acting on cultural variants instead of biological species (Durham 1991; Mesoudi 2011). This process of selection can be analyzed as a change in the relative frequencies of particular musical variants over time.

The most ubiquitous and directionless process is referred to as drift, by which the frequency of variants changes due to random sampling effects, such as the whims of a performer on a given day. However, most of the time, decisions about transmission are biased such that some variants have a greater probability of being selected than others. In these cases, selection pressures are described by theorists as being either directional (e.g., music becoming more appealing to listeners over time; MacCallum et al. 2012), stabilizing (i.e., reducing variability, as Serrà et al. 2012 argue has occurred for chord progressions in Western pop music since 1955), or disruptive/diversifying (i.e., increasing variability by favoring extreme styles, as occurred in twentieth-century modernist music; Ross 2007).

These transmission biases can, in some cases, be content-dependent, such as when music is favored due to its intrinsic aesthetic properties. The lack of such intrinsic aesthetic appeal has been proposed as an explanation for the inability of much post-tonal twentieth-century music to find a wide audience (Ross 2007). In many cases, however, contextdependent biases occur, important examples being "conformist bias" (i.e., the copycat tendency to favor cultural variants that are currently widespread in the population) and "prestige bias" (i.e., the tendency to favor cultural variants associated with highly regarded individuals, such as celebrities or political elites), which exert effects above and beyond the intrinsic features of the music itself (Boyd and Richerson 1985; Mesoudi 2011). Context-dependent biases are particularly notable in politically or economically motivated forms of musical selection, such as those associated with globalization, colonization, or conquest, including propaganda, censorship, or even genocide (Brown and Volgsten 2006).

Overall, through the cultural-evolutionary processes of transmission, variation and selection, the relative frequencies of cultural variants change over time and location. Sometimes, completely novel variants appear out of the blue and show transient spikes in frequency - such as occurs with songs on "viral" YouTube videos - and, in other cases, enduring components of a culture's musical heritage become outlawed overnight due to radical acts of political censorship, such as occurred with the music of Mendelssohn in Nazi Germany (Levi 1990; Haas 2013).

\section{3) Music and Human History}

\section{How can music be used as a tool for the reconstruction of human history?}

The issue of "history" has two complementary facets in comparative musicology. The first deals with music history, i.e., how music itself undergoes changes over time and location. It examines both changes occurring within a single location and the geographic dispersion of musical styles, including the blending of styles that occurs as a result of cultural interaction. The combination of the two helps explain the geographic patterns in musical maps of the world. The second facet deals with human history and how music can serve as a tool to aid in the reconstruction of population history, including patterns of migration and interaction that have occurred from recent times all the way back to the migration of humans out of Africa tens of thousands of years ago.

The first topic was covered in our discussion of cultural evolution in Issue 2 above, where we discussed the mechanisms of both musical change (e.g., random mutation, directed innovation, drift, borrowing, blending) and geographic dispersion of 
musical styles (e.g. migration/diffusion, colonialism, globalization). Therefore, the study of music's cultural evolution and the study of music history are isomorphic.

With this background, the key question for this issue becomes: Given an understanding of the mechanisms of musical change and the geographic distribution of musical styles across world regions, how can we use these historical and geographic patterns as an analytical tool to shed light on the history of human populations more generally? A number of biological and cultural features have been used successfully as markers of human population history spanning the course of tens of thousands of years. These features include genes (such as mitochondrial, Y-chromosome, and autosomal DNA), languages, physical artifacts (e.g., pottery), and historical documents (Cavalli-Sforza et al. 1994; Bellwood and Renfrew 2002; Diamond and Bellwood 2003). Music has an amazing but untapped potential to complement these other markers.

Using music to explore population history requires not only an appropriate sampling procedure, classification methodology (Issue 1), and understanding of musical change (Issue 2), but also a comparative methodology that allows us to examine correlations (or conversely dissociations) between music and other markers of human history. In other words, we need methods that can allow us to quantify the extent to which geographic patterns of musical style correlate with geographic patterns of genes, languages, and other markers (Mantel 1967; Pamjav et al. 2012; Brown et al. forthcoming). If such correlations can indeed be shown to exist, how can we account for them? Standard models of coevolution in population genetics contrast a branching model of shared ancestry and migration (Cavalli-Sforza et al. 1988; Cavalli-Sforza, Menozzi, and Piazza 1994) with an isolation-by-distance model by which genes and other features diffuse between geographic neighbors, possibly independently of one another (Wright 1943). These models differ based on the degree of borrowing between neighboring populations and the time of origin of shared features, with important consequences for interpreting correlations between music and other markers.

Previous work in comparative musicology has already begun to examine how the patterns of musical diversity across regions can be used to trace human migrations across vast spans of time and geography (Lomax 1968; Erickson 1976; Nattiez 1999; Callaway 2007; Pamjav et al. 2012; Brown et al. forthcoming). Most controversially, Grauer (2006, 2011) proposed that a distinctive form of hocket polyphony found in modern-day music of Central African Pygmies and Khoisan "Bushmen" is a musical marker of the spread of humans out of Africa dating back tens of thousands of years, although this hypothesis has been disputed (Stock 2006; Leroi and Swire 2006). On a more recent time scale, ethnomusicological studies of musical diasporas during the past few hundred years suggest that music is deeply integrated into broader cultural migrations, even when native languages are replaced (Turino and Lea 2004). In some cases, diasporic communities preserve traditional musical styles more faithfully than do the homeland cultures (Sharp 1932; Miller 2009). In contrast, longdistance diffusion of musical styles through, for example, globalization, can result in situations whereby music is dissociated from actual population movement and thus from the people who make it. This has occurred particularly following the rise of nation-states, world religions, global economies, and the "culture industry" (Adorno and Bernstein 2001; Anderson 1991; Appadurai 1996). The fact that music can diffuse independently of population movements (i.e., migration) means that it is important to analyze musical and non-musical markers independently before attempting to compare them, thereby avoiding circular arguments. In addition, different types of musics or musical features might reflect different layers of history, as seen by the joint presence of contemporary pop, Christian hymns, and pre-contact musical styles throughout Oceania (Nettl et al. 1998). 


\section{4) Musical Universals}

Which musical features are found most universally across cultures, and which are more variable and culture-specific?

The topic of universals applies not just to musical sound alone but to all aspects of musical behavior and meaning as well (see Issue 1). Therefore, it is just as reasonable to examine universal trends in performance contexts, gender roles, and song texts as it is in features such as the rhythmic patterns and scales that emanate from these behavioral practices (Brown and Jordania 2013). In addition, any approach to musical universals is critically dependent upon how we choose to describe and classify music, as outlined above in Issue 1 about classification features.

The quest for musical universals is one of the key objectives of comparative musicology. While many different types of evidence can be used to bolster arguments about universals, the study of musical universals must be based, first and foremost, on cross-cultural analyses of music and musical behavior. It cannot be based exclusively on cognitive psychology, child development, neuroimaging findings, evolutionary arguments, or comparisons between human and animal behavior. All of those findings can provide critical support to arguments about musical universals, but the basic evidence must come from synthesizing information from the musics of as many cultures as possible. In other words, musical universals are the proper domain of comparative musicology and are one of its most important products.

\section{a) Types of universals}

The strongest objection that has been put forth in opposition to the concept of musical universals is that universals have to be absolute and exceptionless. In reality, there is no feature of human behavior or human culture that is absolute, and yet this has not stopped scholars in most disciplines of the human sciences from discussing cross-cultural trends in these areas. Universals are a common topic of discussion in linguistics (Greenberg 1966; Chomsky 1981; Good 2008) and anthropology (Brown 1991), among many other disciplines. The important point is that the universals identified in all of these areas are statistical and probabilistic. They represent reliable cross-cultural trends, not absolutes. Thus, for example, Brown and Jordania (2013) proposed a "gradient of universality" in their listing of seventy putative cross-cultural universals of musical sound and behavior, ranging from what they called "conserved universals" (the most prevalent) such as octave equivalence, to "predominant patterns" such as religious/ritual contexts for musical performance, to "common patterns" such as the use of aerophones in a culture's instrumental ensemble. There are of course exceptions to all generalization in all fields, but the existence of exceptions - and of diversity more generally-should not preclude serious discussion of cross-cultural trends.

The study of musical universals includes an analysis of conditional or implicational universals, where combinations of features are commonly associated with one another cross-culturally, whether or not each feature on its own is unusually common. It also includes individual features that are highly prevalent all on their own, called nonimplicational universals. For example, the association of isochronous meters with group performance mentioned by Brown and Jordania (2013) would qualify as an implicational universal, whereas the prevalence of isochronous meters would be a non-implicational universal.

\section{b) Causes of universality}

To the extent that reliable cross-cultural trends can be shown to exist as a result of detailed comparative analyses, two types of explanationscultural and biological — are typically put forward to account for them. We can think about these factors as reflecting shared history versus shared genes, respectively. As expounded in Issue 3 above, many manifestations of culture, including songs and instruments, have diffused throughout the world via historical processes of migration and contact. Thus, the analysis of cross-cultural trends needs to account for the degree of relatedness between the cultures, an issue known as "autocorrelation" or "Galton's problem" (Naroll 1961). When trends exist even after controlling for historical relatedness, a common biological explanation of universality is that the trait is encoded at the genetic 
level (i.e., it is hardwired into the brain) and that it is a biological feature of our species as a whole, usually due to natural selection processes (elaborated in Issue 5 below; Barkow, Cosmides, and Tooby 1992). This need not be conceptualized as hard-core determinism, but as a series of "constraints" that have a moderating effect on the form that the behavior can take.

As with any nature-nurture dichotomy, these biological and historical explanations are not necessarily mutually exclusive. One important factor that straddles biological and cultural constraints relates to convergent evolution due to similar selection pressures arising from similar environmental or cultural conditions (discussed in Issues $2 \mathrm{a}$ and $2 \mathrm{~b}$ ). For example, some evidence suggests that male performers tend to outnumber female performers throughout the world, but it appears likely that this is due more to the crosscultural prevalence of patriarchy than to any biological constraints on female musicality (Koskoff 1987).

Like the existence of diversity, this complexity does not inherently doom the analysis of musical universals, but it does necessitate great care in sample selection, analysis, and interpretation. Regarding sample selection, we talked about regional versus remote comparison in relation to song sampling for comparative projects (Issue 1b). It is interesting to point out how these two types of comparison have been employed to support arguments for universality mechanisms. Regional comparisons have generally been used to support cultural explanations, whereas remote comparisons have generally been used to bolster arguments about biological constraints.

\section{5) Biological Evolution of Music}

What is music, and how did it evolve? What are the fundamental functions of music for the human species?

Biological approaches to music evolution focus on two related issues: origins and functions (discussed in $5 \mathrm{a}$ and $5 \mathrm{~b}$, respectively). During the Enlightenment, it was commonplace to discuss music's origins. Condillac (1746/1971) and Rousseau (1781/1986) wrote popular essays in the eighteenth century about the origins of music and about music's evolutionary connection with language. Enthusiasm for the topic continued unabated into the nineteenth century, first with the writings of Spencer $(1857,1890)$ and Darwin (1871, 1872 ) in England, and later with the writings of the early comparative musicologists in Germany (e.g., Stumpf 1911/2012). However, after the decline of comparative musicology in the mid-twentieth century, the topic of music origins all but disappeared from musicological discussion.

There has been a resurgence of interest in music evolution in recent years (Wallin, Merker, and Brown 2000), but much of it has come from evolutionary psychology and music cognition, rather than from musicology. In addition, much of the evidence being presented to validate evolutionary hypotheses is based solely on Western music, which is being employed in experiments examining perception, brain activation, and child development in Western subjects. What is missing is a cross-cultural database of musical behavior that could provide a more balanced testing ground for evolutionary hypotheses of music making. It is here where our new perspective on comparative musicology offers great promise in providing the appropriate data for evaluating evolutionary hypotheses.

\section{a) Origins}

Structural (or phylogenetic) approaches consider the evolutionary history of the human species and provide proposals for how music might have emerged in anatomically modern humans over the course of perhaps millions of years. Many phylogenetic models focus on the evolutionary relationship between music and language: Did the two evolve independently or in tandem? Enlightenment thinkers like Condillac and Rousseau argued strongly that these evolutions were intertwined, and more recent thinkers have adopted similar ideas, including the view that song and speech sit along a single musilinguistic continuum, rather than being completely independent processes 
(Brown 2000a; Mithen 2005; Savage et al. 2012). Such an evolutionary hypothesis is in no way inconsistent with music and language having domain-specific features (Peretz and Coltheart 2003).

Phylogenetic approaches often look to animal models of music-like phenomena. For example, primate models of human behavioral evolution provide clues regarding social capacities that may have underlain musical evolution, including interactive features related to group structure and social calling. Likewise, acoustic models of animal vocalization in more distantly related speciesespecially the socially learned songs of some birds and whales - provide useful information that allows us to distinguish analogy (independent evolution) from homology (shared ancestry) in the evolution of music. Overall, the combination of cross-species and cross-cultural work will permit a deep understanding of the biological underpinnings of musicality, such as common genetic/neural constraints on vocal learning (Jarvis 2004) and metric entrainment (Patel et al. 2009; Schachner et al. 2009), or genetic contributions to individual differences in musicality (e.g., "congenital amusia"; Peretz et al. 2002).

A major shortcoming in early comparative musicology was the assumption that contemporary tribal cultures, such as hunter-gatherer cultures, represent the ancestral state of human behavior and thus can serve as models of ancient humans (Nettl and Bohlman 1991). The degree to which this is true continues to be a topic of heated debate (Marlowe 2005). However, it has become clear that applying detailed knowledge of population history to such matters (Issue 3) allows for much stronger conclusions when evaluating hypotheses about origins. For example, while there may be truth to Grauer's (2006) theory that musical similarities between Pygmies and Bushmen reflect ancient musical origins, testing such a theory requires sophisticated phylogenetic models that incorporate detailed cross-disciplinary information about both past and present diversity wherever possible. It cannot simply be based on assumptions of either biological or cultural "inertia" (Stock 2006; Leroi and Swire 2006).

\section{b) Functions}

Functional or Darwinian approaches to music evolution consider the functional consequences of music for the individuals and groups that make music, i.e., how music might contribute to our evolutionary fitness and that of our ancestors in terms of both survival and reproduction. In other words, they look at the adaptive properties of music making as related to music's benefits and costs. (As mentioned in Issue 2a, our discussion of Darwinism here has nothing at all to do with the widely discredited Social Darwinism of the nineteenth century.)

While the evolution of language provides obvious survival advantages (Christiansen and Kirby 2003), music's apparent lack of individual survival value led Darwin (1871) to describe music as "among the most mysterious" faculties with which humans are endowed. This sparked a number of theories regarding the biological evolution of music (reviewed in Brown 2000b; Jordania, 2006, 2011; Fitch 2006; Patel 2008, 2010). While some theories view music as a non-adaptive byproduct of non-musical functions (Patel 2008) - such as language (Spencer 1890; Pinker 1997) - many see it as as an adaptive function that evolved through Darwinian mechanisms of natural selection. However, controversy has raged over whether music's adaptive properties operate at the level of the individual or the group. While few people support the position that music evolved due to its effects on individual survival per se (although see Jordania 2011 on defense against predation), Miller (2000) called for a revival of Darwin's (1871) hypothesis of sexual selection for music, which posits that music has its major adaptive effect on individual reproductive success. According to this view, music functions primarily as an aesthetic display used to attract mates and thereby increase the chances for reproductive encounters. This is in contrast to the hypothesis of group selection (or the related mechanisms of kin selection and multilevel selection), which argues that music's adaptive functions occur primarily at the group level, notably through its promotion of cooperation and cohesion (Brown 2000b; Cross 2003; Jordania, 2006, 2011), including the special case of mother-infant bonding (Trehub 2000; Dissanayake 2000). While the 
anthropology of music has been strongly dominated by notions of group functionality for many decades (Merriam 1964; Nettl 2005), the very idea that natural selection can operate at a level beyond the individual organism is still highly contentious within the field of evolutionary biology (Okasha 2006; Wilson and Wilson 2007; Abbot et al. 2011).

Debates about music's evolutionary adaptiveness raise a host of important questions about how music is made - by which individuals, in what contexts, and to what ends. Music clearly serves a wide variety of roles within cultures, and so an evaluation of functional hypotheses about music requires cross-cultural ethnographic analyses of the contents, performers (e.g., gender), contexts, and audiences of musical performance. As per our earlier discussion of classification (Issue 1), such analyses have to examine the relative frequencies of behavioral patterns across cultures, with the aim of testing the predictions of competing selectionist hypotheses. For example, sexual selection hypotheses might predict that music is performed predominantly by men of reproductive age towards women of reproductive age in the context of courtship, with lyrics, body movements, and symbolisms suggestive of suitability for mating, as related to health, physical/technical prowess, or possession of resources. By contrast, group selection hypotheses might predict that music is performed predominantly by inclusive groups in contexts of collective importance, with texts designed to increase group cohesion or to resolve social conflicts, such as related to group identity, religious practice, communal work, or inter-group relations. Such controversies can only be resolved by detailed comparative analyses of musical behavior. Such analyses need to weigh the benefits of music making against the costs in terms of time, money, energy, and attracting unwanted attention. Ideally, they should also analyze actual fitness consequences in terms of average numbers of offspring produced as a function of generating and experiencing music.

Figure 2 provides a summary outline of key theoretical issues and terms in comparative musicology across the five issues discussed above.

\section{1) Classification, clustering, and maps of music}

- Musical sound, behavior, and concept

- Phenetic vs. phylogenetic classification

a) Units: Notes; phrases; songs; genres; (ethnolinguistically defined) cultures; geographic regions

b) Sampling: Inclusion criteria; sample size; remote vs. regional comparison

c) Features: Characters; character-states; ordinal vs. nominal characters; emic vs. etic approaches

d) Quantification: Degrees of similarity; relative frequencies; clustering; "cantogroups" (stylistic song-types); musical maps; within-culture vs. between-culture diversity

\section{2) Cultural evolution of music}

a) Transmission: Vertical vs. horizontal; convergent evolution; trees; networks; jungles; admixture

b) Variation: Mutation vs. innovation; borrowing/imitation; blending; monogenesis vs. convergent evolution (polygenesis)

c) Selection: Drift; directional vs. stabilizing vs. diversifying selection; content-dependent vs. context-dependent transmission biases

3) Music and human history

- Genes; languages; artifacts; documents

- Correlation vs. dissociation; branching coevolution vs. isolation-by-distance

\section{4) Musical universals}

a) Types: Statistical vs. absolute; implicational vs. non-implicational

b) Causes: Cultural vs. biological

\section{5) Biological evolution of music}

a) Origins: Musilinguistic continuum vs. domain-specific modules; homology vs. analogy

b) Functions: Natural selection; sexual selection; group/kin/multilevel selection

Figure 2. Summary outline of key theoretical issues and terms in comparative musicology (see text for details). 


\section{PART II: OBJECTIONS TO COMPARISON}

The term "comparative musicology" often evokes a negative knee-jerk reaction from those who associate it with a host of methodological and ideological problems in the work of the early comparative musicologists. We hope that this article's description of the key research areas of our new framework for comparative musicology addresses many of these problems. However, since there is a long history of skepticism regarding musical comparison, we would like to specifically address the most common concerns. Many of these concerns have been addressed by others, most notably Alan Merriam (1982) in his objection to the anti-comparativist views of his contemporaries Mantle Hood and John Blacking.

Complexity. One of the most common objections to comparison is that it is difficult to carry out. Understanding the music of one culture is challenging, and understanding the music of two cultures is even more challenging. In addition, understanding the music of two cultures using a common set of categories that can accommodate the diverse features of these musics is particularly difficult. This problem only becomes magnified as more cultures are included in the analysis. While this objection to comparison is valid, it is not constructive. Comparative musicology faces many of the same challenges as the comparative study of languages, genes, etc. The good news is that comparative musicology can take full advantage of theoretical and methodological advances made in those fields and adapt them to music.

Sound vs. meaning. A second common objection to comparison is that it places excessive emphasis on musical "sound" at the expense of the non-acoustic domains of "behavior" and "concept" (including meaning) that Merriam (1964) outlined. Historically speaking, this criticism has been a valid one, as the early comparative musicologists - many of them psychoacousticians - were particularly interested in acoustic features, such as scales, and had far better access to sound recordings and musical instruments than to ethnographic resources, such as field interviews or films. Hence, most of their analyses did not address the context or social meaning of music. However, in thinking about the new comparative musicology, we have argued above that there is a great need to bring comparative methods to the study of musical behavior (Feld 1984) and meaning (Nattiez 1990), in exactly the same way that they have been applied to many other ethnographic domains outside of music, including social structure (Murdock 1967) and language (Levinson and Gray 2012).

Politics. Perhaps the strongest objection to comparative musicology comes from those who associate it with the political and ideological climate of scientific racism and eugenics that was prevalent in late nineteenth- and early twentieth-century Germany, the milieu in which comparative musicology had its roots (Rehding 2000). Such a criticism cannot be laid exclusively against the comparative musicologists, as many of the concepts that they adopted were prominent in the anthropology of their day. Discredited evolutionary notions, such as monogenesis, unilinear progressive evolution, and Social Darwinism, long predated the development of comparative musicology. Likewise, terminology such as "primitive" was endemic to scholarship of all kinds during that period. Darwin and others in nineteenth-century England referred to tribal peoples as "savages" and "barbarians," and even Bruno Nettl, one of the founding figures of the field of ethnomusicology, titled his first book Music in Primitive Culture (Nettl 1956). It would be misguided to reject historical scholarship entirely based on concerns about (what are now considered to be) outdated or racialist concepts without considering how we can productively adapt its aims and methods.

Careful reading of the works of figures such as Hornbostel (Wachmann, Christensen, and Reinecke 1975), and Sachs (1962) shows that they were absolutely fascinated by the music that they were describing. Their research, despite containing some outdated evolutionary theorizing, does not come across as disguised racism. They provide the first scholarly descriptions of non-Western music at exactly the time when the first recordings of such music were becoming available. If anything, these works evince the joy of the discovery of new musical worlds. Many of the early comparative musicologists were themselves persecuted because of their Jewish heritage, including Hornbostel and Sachs, who were both exiled by the Nazi regime in 
1933. Since that time, biological anthropology has made spectacular strides in understanding the nature and history of human populations, leading to profoundly new views of human origins that flatly reject biological claims of racial superiority (Cavalli-Sforza, Menozzi, and Piazza 1994; Marks 1995). To avoid the racialist biases of the past, ethnomusicologists should embrace these new findings of anthropology and incorporate them into their research agenda.

Many musicologists who reject comparison today because of its negative political connotations are themselves politically interested in "applied ethnomusicology" (Sheehy 1992), including activism and pedagogy. However, it is difficult to celebrate the world's musical diversity or argue for the need to preserve endangered cultural heritages without placing music cultures in their broader historical and geographic context. Indeed, this was precisely the vision behind Lomax's Cantometrics project and its application in the Global Jukebox and the Association for Cultural Equity (Lomax 1977; Sheehy 1992; Swed 2010). Avoiding the perceived reductionism of comparative analyses may help to avoid an oversimplification of musical complexities, but it also makes it harder to convince the public that music cultures are worthy of study, archiving, funding, or political recognition. Balancing competing ethical dilemmas is a challenge that needs to be addressed constructively, not by summarily rejecting comparative methods.

\section{CONCLUSIONS}

We hope that this review gives a strong sense of the ways in which a new comparative musicology could provide invaluable information not just about music but also about humanity in general. However, such insights can only come about through a fresh commitment to cross-cultural musical comparison. It is important to point out that in many fields of the human sciences, broad explanatory theories are commonplace even when cross-cultural data are rare and difficult to ascertain (Henrich, Heine, and Norenzayan 2010). Such was the case for the early comparative musicologists who put forth broad theories about the world's musics from the limited number of recordings available to them during the time that they were building the first cross-cultural musical archives from scratch. In contrast to this, contemporary ethnomusicologists have accumulated millions of recordings and associated documentation from all over the world but generally lack theories and methods to synthesize these data (Rice 2010).

Much could be gained if ethnomusicologists reincorporated cross-cultural comparison, scientific methodology, and contemporary evolutionary theory into their research program and thereby returned to the big-picture questions of comparative musicology that we have described in this article. However, the evolution of academic disciplines, like that of organisms, is constrained by historical factors, and ethnomusicology today might be too strongly committed to relativism and postmodernism to make a reincorporation of comparativism possible anytime soon. We hope that, in the future, the distinctions between comparative musicology, ethnomusicology, historical musicology, and other subdisciplines will merge into a diverse "musicology" that draws upon a wide variety of theoretical and methodological paradigms, as envisioned by Adler when he first established this field (Adler 1885/1981).

\section{Acknowledgments}

This is a revised and expanded version of material presented at the Symposium on Comparison at the Second International Conference on Analytical Approaches to World Music at the University of British Columbia in May 2012. We are grateful to the many participants who discussed these issues, particularly co-presenters Victor Grauer, Nathalie Fernando, and Jean-Jacques Nattiez, and the formal respondent, Gage Averill, as well as to Tom Currie for helpful comments on a previous version of the manuscript. Some of the material of this article has also been adapted from our Comparative Musicology website at http://compmus.org. In addition, we recently reviewed this material in detail from the perspective of how music can contribute to general anthropological debates about cultural diversity and evolution (Savage and Brown in press). That review was addressed to an audience of francophone 
anthropologists, who have historically had fewer ideological objections to comparison, and should be referred to for a more thorough review of the anthropological literature. This work was supported by a grant to S.B. from the Social Sciences and Humanities Research Council of Canada, and by a Japanese Ministry of Education, Culture, Sports, Science, and Technology Scholarship to P.E.S.

\section{REFERENCES}

Abbot, Patrick, Jun Abe, John Alcock, Samuel Alizon, Joao A. C. Alpedrinha, Malte Andersson, Jean-Baptiste Andre, et al. 2011. "Inclusive Fitness Theory and Eusociality." Nature 471: E1-4. doi:10.1038/nature09831.

Adler, Guido. 1885/1981. "The Scope, Method, and Aim of Musicology." Translated by Erica Mugglestone. Yearbook for Traditional Music 13: 1-21. Adorno, Theodor W., and J. M. Bernstein. 2001. The Culture Industry: Selected Essays on Mass Culture. New York: Routledge.

Anderson, Benedict R. O'G. 1991. Imagined Communities: Reflections on the Origin and Spread of Nationalism. New York: Verso.

Appadurai, Arjun. 1996. Modernity at Large. Minneapolis: University of Minnesota Press.

Barkow, Jerome H., Leda Cosmides, and John Tooby. 1992. The Adapted Mind: Evolutionary Psychology and the Generation of Culture. New York: Oxford University Press.

Bateman, Gregory. 1935. "Culture Contact and Schismogenesis." Man 35: 178-83.

Bayard, Samuel P. 1950. "Prolegomena to a Study of the Principal Melodic Families of BritishAmerican Folk Song." The Journal of American Folklore 63(247): 1-44.

Bellwood, Peter, and Colin Renfrew, ed. 2002. Examining the Farming/language Dispersal Hypothesis. Cambridge: McDonald Institute for Archaeological Research.

Blacking, John. 1971. "Deep and Surface Structures in Venda Music." Yearbook of the International Folk Music Council 3: 91-108. . 1977. "Some Problems of Theory and Method in the Study of Musical Change." Yearbook of the International Folk Music Council 9: 1-26.
Boyd, Robert, and Peter J. Richerson. 1985. Culture and the Evolutionary Process. Chicago: University of Chicago Press.

Brown, Donald E. 1991. Human Universals. Philadelphia: Temple University Press.

Brown, Steven. 2000a. "The 'Musilanguage' Model of Musical Evolution." In The Origins of Music, edited by Nils L. Wallin, Bjorn Merker, and Steven Brown, 271-300. Cambridge: MIT Press.

-. 2000b. "Evolutionary Models of Music: From Sexual Selection to Group Selection.” In Perspectives in Ethology. 13: Evolution, Culture, and Behavior, edited by F. Tonneau and N.S. Thompson, 13:231-81. New York: Plenum Publisher.

Brown, Steven, and Joseph Jordania. 2013. "Universals in the World's Musics." Psychology of Music 41(2): 229-48.

Brown, Steven, Patrick E. Savage, Albert Min-Shan Ko, Mark Stoneking, Ying-Chin Ko, Jun-Hun Loo, and Jean A. Trejaut. Forthcoming. "Correlations in the Population Structure of Music, Genes, and Languages." Proceedings of the Royal Society B: Biological Sciences.

Brown, Steven, and Ulrik Volgsten. 2006. Music and Manipulation: On the Social Uses and Social Control of Music. New York: Berghahn Books.

Bryant, David, and Vincent Moulton. 2004. "Neighbor-Net: An Agglomerative Method for the Construction of Phylogenetic Networks." Molecular Biology and Evolution 21(2): 25565.

Callaway, Ewen. 2007. "Music Is in Our Genes." Nature News. doi:10.1038/news.2007.359.

Cavalli-Sforza, L. Luca, and Marcus W. Feldman. 1981. Cultural Transmission and Evolution: A Quantitative Approach. Princeton: Princeton University Press.

Cavalli-Sforza, L. Luca, Paolo Menozzi, and Alberto Piazza. 1994. The History and Geography of Human Genes. Princeton: Princeton University Press.

Cavalli-Sforza, L. Luca, Alberto Piazza, Paolo Menozzi, and Joanna Mountain. 1988. "Reconstruction of Human Evolution: Bringing Together Genetic, Archaeological, 
and Linguistic Data." Proceedings of the National Academy of Sciences 85(16): 6002-6.

Chomsky, Noam. 1981. Lectures on Government and Binding. Dordrecht: Foris.

Christiansen, Morten H., and Simon Kirby. 2003. "Language Evolution: Consensus and Controversies." Trends in Cognitive Sciences 7(7): 300-307.

Clarke, Eric F., and Nicholas Cook, eds. 2004. Empirical Musicology: Aims, Methods, Prospects. Oxford: Oxford University Press.

Condillac, Etienne Bonnot de. 1746/1971. An Essay on the Origin of Human Knowledge. Translated by R. G. Weyant. Gainesville: Scholars' Facsimiles \& Reprints.

Cross, Ian. 2003. "Music, Cognition, Culture, and Evolution." In The Cognitive Neuroscience of Music, edited by Isabelle Peretz and Robert J. Zatorre, 930:42-56. Oxford: Oxford University Press.

Darwin, Charles. 1859. On the Origin of Species by Means of Natural Selection, or the Preservation of Favoured Races in the Struggle for Life. London: John Murray. - 1871. The Descent of Man, and Selection in Relation to Sex. London: John Murray.

- 1872. The Expression of the Emotions in Man and Animals. London: John Murray.

Diamond, Jared, and Peter Bellwood. 2003. "Farmers and Their Languages: The First Expansions." Science 300(5619): 597-603.

Dissanayake, Ellen. 2000. "Antecedents of the Temporal Arts in Early Mother-infant Interaction." In The Origins of Music, edited by Nils L. Wallin, Bjorn Merker, and Steven Brown, 389-410. Cambridge, MA: MIT Press.

Doolittle, W. Ford. 1999. "Phylogenetic Classification and the Universal Tree." Science 284(5423): 2124-28.

Driver, Harold E. 1970. "Review of A. Lomax, Folk Song Style and Culture." Ethnomusicology 14(1): 57-62.

Durham, William H. 1991. Coevolution: Genes, Culture, and Human Diversity. Stanford, CA: University of California Press.

Erickson, Edwin E. 1976. "Tradition and Evolution in Song Style: A Reanalysis of Cantometric
Data." Cross-Cultural Research 11(4): $277-$ 308.

Feld, Steven. 1984. "Sound Structure as Social Structure." Ethnomusicology 28(3): 383-409.

Fitch, W. Tecumseh. 2006. "The Biology and Evolution of Music: A Comparative Perspective." Cognition 100: 173-215.

Good, Jeff. 2008. Linguistic Universals and Language Change. New York: Oxford University Press.

Grauer, Victor A. 2006. "Echoes of Our Forgotten Ancestors." The World of Music 48(2): 5-59.

- 2011. Sounding the Depths: Tradition and the Voices of History. CreateSpace.

Gray, Russell D., David Bryant, and Simon J. Greenhill. 2010. "On the Shape and Fabric of Human History." Philosophical Transactions of the Royal Society B: Biological Sciences 365: 3923-33.

Greenberg, Joseph H. 1957. Essays in Linguistics. Chicago: University of Chicago Press.

- 1966. Language Universals, with Special Reference to Feature Hierarchies. The Hague: Mouton.

Haas, Michael. 2013. Forbidden Music: The Jewish Composers Banned by the Nazis. New Haven: Yale University Press.

Harris, Marvin. 1976. "History and Significance of the Emic/Etic Distinction." Annual Review of Anthropology 5(1): 329-50.

Henrich, Joseph, Steven J. Heine, and Ara Norenzayan. 2010. "The Weirdest People in the World?" The Behavioral and Brain Sciences 33: 61-135.

Henry, Edward O. 1976. "The Variety of Music in a North Indian Village: Reassessing Cantometrics.” Ethnomusicology 20(1): 49-66.

Herskovits, Melville J. 1945. "Problem, Method, and Theory in Afroamerican Studies." Afroamerica 1: 5-24.

Hornbostel, Erich M. von, and Curt Sachs. (1914) 1961. "Classification of Musical Instruments." Trans. Anthony Baines and Klaus P. Wachmann. Galpin Society Journal 14: 3-29.

Huron, David. 1999. "Music and Mind: Foundations of Cognitive Musicology (The 
1999 Ernest Bloch Lectures).” Berkeley, CA: University of California.

International Folk Music Council. 1955. "Resolutions." Journal of the International Folk Music Council 7: 23.

Jarvis, Erich D. 2004. "Learned Birdsong and the Neurobiology of Human Language." Annals of the New York Academy of Sciences 1016: 74977.

Jordania, Joseph. 2006. Who Asked the First Question? The Origins of Human Choral Singing, Intelligence, Language and Speech. Tblisi: Logos.

. 2011. Why do People Sing? Music in Human Evolution. Tblisi: Logos.

Koskoff, Ellen, ed. 1987. Women and Music in Cross-cultural Perspective. New York: Greenwood Press

Kroeber, Alfred L. 1948. Anthropology. New York: Harcourt.

Leroi, Armand M., and Jonathan Swire. 2006. "The Recovery of the Past." The World of Music 48(3): 43-54.

Levi, Erik. 1990. "The Aryanization of Music in Nazi Germany." The Musical Times 131(1763): 19-23.

Levinson, Stephen C., and Russell D. Gray. 2012. "Tools from Evolutionary Biology Shed New Light on the Diversification of Languages." Trends in Cognitive Sciences 16(3): 167-73.

Lewis, M. Paul, ed. 2009. Ethnologue: Languages of the World. Dallas: SIL International. 16th ed. Dallas: SIL International.

Lomax, Alan, ed. 1968. Folk Song Style and Culture. Washington, DC: American Association for the Advancement of Science.

Lomax, Alan. 1976. Cantometrics: An Approach to the Anthropology of Music. Berkeley: University of California Extension Media Center.

-. 1977. "Appeal for Cultural Equity." Journal of Communication.

Lomax, Alan, Irmgard Bartenieff, and Forrestine Paulay. 1968. "The Choreometric Coding Book." In Folk Song Style and Culture, edited by Alan Lomax, 262-73. Washington, DC: American Association for the Advancement of Science.
MacCallum, Robert M., Matthias Mauch, Austin Burt, and Armand M. Leroi. 2012. "Evolution of Music by Public Choice." Proceedings of the National Academy of Sciences 109(30): 12081-86.

Mantel, Nathan. 1967. "The Detection of Disease Clustering and a Generalized Regression Approach." Cancer Research 27(2 Part 1): 209-20.

Marks, Jonathan. 1995. Human Biodiversity: Genes, Race, and History. New York: Aldine de Gruyter.

Marlowe, Frank W. 2005. "Hunter-gatherers and Human Evolution." Evolutionary Anthropology 14 (2): 54-67.

Merriam, Alan P. 1964. The Anthropology of Music. Evanston: Northwestern University Press.

-1 1977. "Definitions of 'Comparative Musicology' and 'Ethnomusicology': An Historical-theoretical Perspective." Ethnomusicology 21(2): 189-204.

-1 1982. "On Objections to Comparison in Ethnomusicology." In Cross-cultural Perspectives on Music, edited by Robert Falck and Timothy Rice, 175-89. Toronto: University of Toronto Press.

Mesoudi, Alex. 2011. Cultural Evolution: How Darwinian Theory Can Explain Human Culture and Synthesize the Social Sciences. Chicago: University of Chicago Press.

Middleton, Richard. 1990. Studying Popular Music. Milton Keynes, England: Open University Press.

Miller, Geoffrey F. 2000. "Evolution of Human Music Through Sexual Selection." In The Origins of Music, edited by Nils L. Wallin, Bjorn Merker, and Steven Brown, 329-60. Cambridge, MA: MIT Press.

Miller, Ivor. 2009. Voice of the Leopard: African Secret Societies and Cuba. Jackson: University Press of Mississippi.

Mithen, Steven J. 2005. The Singing Neanderthals: The Origins of Music, Language, Mind, and Body. London: Weldenfeld \& Nicholson.

Murdock, George P. 1967. "Ethnographic Atlas: A Summary." Ethnology 6(2): 109-236.

Naroll, Raoul. 1961. “Two Solutions to Galton's Problem." Philosophy of Science 28(1): 15-39. 
Nattiez, Jean-Jacques. 1990. Music and Discourse: Toward a Semiology of Music. Trans. Carolyn Abbate. Princeton: Princeton University Press. - 1999. "Inuit Throat-games and Siberian Throat Singing: A Comparative, Historical, and Semiological Approach." Ethnomusicology 43(3): 399-418.

Nettl, Bruno. 1956. Music in Primitive Culture. Cambridge: Harvard University Press.

. 2005. The Study of Ethnomusicology: Thirty-one Issues and Concepts. 2nd ed. Champaign: University of Illinois Press.

Nettl, Bruno, and Philip Vilas Bohlman, eds. 1991. Comparative Musicology and Anthropology of Music: Essays on the History of Ethnomusicology. Chicago: University of Chicago Press.

Nettl, Bruno, Ruth Stone, James Porter, and Timothy Rice, eds. 1998. The Garland Encyclopedia of World Music [10 Volumes; 9 $C D s]$. New York: Routledge.

Okasha, Samir. 2006. Evolution and the Levels of Selection. Oxford: Oxford University Press.

Pagel, Mark, and Ruth Mace. 2004. "The Cultural Wealth of Nations." Nature 428(6980): 27578.

Pamjav, Horolma, Zoltán Juhász, Andrea Zalán, Endre Németh, and Bayarlkhagva Damdin. 2012. "A Comparative Phylogenetic Study of Genetics and Folk Music." Molecular Genetics and Genomics 287(4): 337-49.

Patel, Aniruddh D. 2008. Music, Language and the Brain. Oxford: Oxford University Press.

. 2010. "Music, Biological Evolution, and the Brain." In Emerging Disciplines, edited by M. Bailar, 91-144. Houston: Rice University Press.

Patel, Aniruddh D., John R. Iversen, Micah R. Bregman, and Irena Schulz. 2009. "Experimental Evidence for Synchronization to a Musical Beat in a Nonhuman Animal." Current Biology 19: 827-830.

Peretz, Isabelle, Julie Ayotte, Robert J. Zatorre, Jacques Mehler, Pierre Ahad, Virginia B. Penhune, and Benoît Jutras. 2002. "Congenital Amusia: A Disorder of Fine-grained Pitch Discrimination." Neuron 33(2): 185-91.
Peretz, Isabelle, and Max Coltheart. 2003. "Modularity of Music Processing." Nature Neuroscience 6(7): 688-91.

Perlman, Marc, and Carol L. Krumhansl. 1996. "An Experimental Study of Internal Interval Standards in Javanese and Western Musicians." Music Perception 14(2): 95-116.

Pinker, Steven. 1997. How the Mind Works. New York: Norton.

Pritchard, Jonathan K., Matthew Stephens, and Peter Donnelly. 2000. "Inference of Population Structure Using Multilocus Genotype Data." Genetics 155: 945-59.

Rehding, Alexander. 2000. "The Quest for the Origins of Music in Germany Circa 1900." Journal of the American Musicological Society 53(2): 345-85.

Rice, Timothy. 2010. "Disciplining Ethnomusicology: A Call for a New Approach." Ethnomusicology 54(2): 318-25.

Ross, Alex. 2007. The Rest Is Noise: Listening to the Twentieth Century. New York: Farrar, Straus and Giroux.

Rousseau, Jean-Jacques. 1781/1986. Essay on the Origin of Languages. Trans. J. H. Moran and A. Gode. Chicago: University of Chicago Press.

Rzeszutek, Tom, Patrick E. Savage, and Steven Brown. 2012. "The Structure of Cross-cultural Musical Diversity." Proceedings of the Royal Society B: Biological Sciences 279: 1606-12.

Sachs, Curt. 1962. The Wellsprings of Music. Edited by Jaap Kunst. The Hague: M. Nijhoff.

Savage, Patrick E., and Steven Brown. Forthcoming. "Mapping Music: Cluster Analysis of Song-type Frequencies Within and Between Cultures." Ethnomusicology 58(1).

—. In press. "Vers une nouvelle musicologie comparative: Cinq domaines et débats clés." Anthropologie et Sociétés 37(3).

Savage, Patrick E., Emily Merritt, Tom Rzeszutek, and Steven Brown. 2012. "CantoCore: A New Cross-cultural Song Classification Scheme." Analytical Approaches to World Music 2(1): 87-137.

Schachner, Adena, Timothy F. Brady, Irene M. Pepperberg, and Marc D. Hauser. 2009. 
"Spontaneous Motor Entrainment to Music in Multiple Vocal Mimicking Species." Current Biology 19: 831-36.

Schneider, Albrecht, ed. 2008. Systematic and Comparative Musicology: Concepts, Methods, Findings. Frankfurt: Peter Lang.

Seeger, Charles, ed. 1966. Versions and Variants of the Tunes of Barbara Allen [1 Casette]. Washington, DC: Archive of American Folk Song, Library of Congress. AFS L 54.

Serrà, Joan, Álvaro Corral, Marián Boguñá, Martín Haro, and Josep Ll. Arcos. 2012. "Measuring the Evolution of Contemporary Western Popular Music." Scientific Reports 2 (521): 16. doi:10.1038/srep00521.

Sharp, Cecil J. 1932. English Folk Songs from the Southern Appalachians. London: Oxford University Press.

Sheehy, Daniel. 1992. "A Few Notions About Philosophy and Strategy in Applied Ethnomusicology." Ethnomusicology 36(3): 323-36.

Spencer, Herbert. 1857. "The Origin and Function of Music." Fraser's Magazine 56: 396-408.

_. 1875. "Progress: Its Law and Cause." In Illustrations of Universal Progress: A Series of Discussions, edited by Herbert Spencer, 1-60. New York: D. Appleton \& Company.

- 1890. "The Origin of Music." Mind 15: 449-68.

Stevens, S. S. 1946. "On the Theory of Scales of Measurement." Science 103: 677-80.

Stock, Jonathan P.J. 2006. "Clues from Our Present Peers? A Response to Victor Grauer." The World of Music 48(2): 73-91.

Stumpf, Carl. 1911/2012. The Origins of Music. Translated by D. Trippett. Oxford: Oxford University Press.

Swed, John. 2010. Alan Lomax: The Man Who Recorded the World. New York: Viking.

Tehrani, Jamshid J, Mark Collard, and Stephen J Shennan. 2010. "The Cophylogeny of Populations and Cultures: Reconstructing the
Evolution of Iranian Tribal Craft Traditions Using Trees and Jungles." Philosophical Transactions of the Royal Society B: Biological Sciences 365(1559): 3865-74.

Tëmkin, Ilya, and Niles Eldredge. 2007. "Phylogenetics and Material Cultural Evolution." Current Anthropology 48(1): 14654.

Tenzer, Michael, ed. 2006. Analytical Studies in World Music. New York: Oxford University Press.

Toner, P.G. 2007. "The Gestation of Cross-cultural Music Research and the Birth of Ethnomusicology." Humanities Research 14(1): 85-110.

Trehub, Sandra. 2000. "Human Processing Predispositions and Musical Universals." In The Origins of Music, edited by Nils L. Wallin, Bjorn Merker, and Steven Brown, 427-48. Cambridge, Massachusetts: MIT Press.

Turino, Thomas, and James Lea. 2004. Identity and the Arts in Diaspora Communities. Warren, MI: Harmonie Park Press.

Tzanetakis, George, Ajay Kapur, W. Andrew Schloss, and Matthew Wright. 2007. "Computational Ethnomusicology." Journal of Interdisciplinary Music Studies 1(2): 1-24.

Wachmann, Klaus P., Dieter Christensen, and HansPieter Reinecke, eds. 1975. Hornbostel Opera Omnia. The Hague: Marinus Nijhoff.

Wallin, Nils L., Bjorn Merker, and Steven Brown. 2000. The Origins of Music. Edited by Nils L. Wallin, Bjorn Merker, and Steven Brown. Cambridge: MIT Press.

Whiten, Andrew, Robert A. Hinde, Christopher B. Stringer, and Kevin N. Laland. 2012. Culture Evolves. Oxford: Oxford University Press.

Wilson, David S., and Edward O. Wilson. 2007. "Rethinking the Theoretical Foundation of Sociobiology." The Quarterly Review of Biology 82(4): 1-57.

Wright, Sewall. 1943. "Isolation by Distance." Genetics 28: 114-38. 